\title{
Cognitive analysis of eco-economic processes
}

\author{
Mikhail Rozin ${ }^{1, *}$, Valery Svechkarev ${ }^{1}$, Lidiya Novoseltseva $^{2}$, Anton Ivanov ${ }^{1}$, Zhanna \\ Tumakova $^{1}$ \\ ${ }^{1}$ Southern Federal University, Bolshaya Sadovaya str., 105/42 Rostov-on Don, 344000, Russia, \\ ${ }^{2}$ PJSC «Rostvertol», Nagibina str. 30, Rostov-on Don, 344000, Russia
}

\begin{abstract}
It has been noted that the $21^{\text {st }}$ century saw significant changes in public views on the economy-ecology relationship. Growing number of applied studies of eco-economic issues as well as the need to comprehend achieved results brought the use of cognitive analytics to the fore. Cognitive model provides a holistic view on the existing eco-economic process through its graphic representation reflecting nature and dynamics of causal relationships. Cognitive analysis of the conventional models of eco-economic process revealed that they mainly focus on economic procedures while environmental issues being shifted towards the periphery. Likewise, the traditional model essentially limits production development by ecological requirements while environmental condition is inherently impaired and requires further restoration or, at the very least, decontamination. The new models of manufacturing organization must aim to improve human environment as a whole and base on a zero-waste production principle where underused resources and raw materials are considered as waste. This article presents a cognitive model of green manufacturing in the shape of a multi-circuit system with all the circuits involved in the zero-waste production cycle. Considering that all circuits employ positive feedback, they initiate growth and mutually support consistent operation of an enterprise. A zero-waste enterprise can and should develop in cooperation with other enterprises that consciously or implicitly (formally) implement sustainable manufacturing plans.
\end{abstract}

\section{Introduction}

The 21 st century saw significant changes in public views on the economy-ecology relationship. Today it is only natural to consider actual socio-eco-economic situation in regional and national development [1]. "Claims to improve quality of life, ensure comfortable living conditions and preserve natural environment are more actively brought to the forefront" [2]. Basic Principles of State Policy in the Area of Environmental Development of the Russian Federation have been defined through 2030 including specific arrangements and models to put technological innovations in effective compliance with the environmental requirements [3]. Current conditions increase responsibility for the decisions being taken and, consequently, boost demand for the models of eco-economic processes that can provide insight into the existing eco-economic situation. Complex combination of

*Corresponding author: idpr@bk.ru 
the initial and predictable ecological factors, various strategies of economic development and potential scenarios for technology implementation suggests that multiple models should be used at all stages and on all managerial levels dealing with eco-economical problems. The most widespread methods and tools are the ones used to model the environmental impact of manufacturing industries and to predict the dynamics of environmental pollution (for examples refer to [4-6]). The growing number of applied studies of the eco-economic issues as well as the need to comprehend the achieved results brought the use of cognitive analytics to the fore $[7,8]$.

\section{Materials and Methods}

The present article should be construed as an attempt to apply cognitive analytics methodology to the research into the eco-economic processes and systems and particularly to the analysis of interactions between structural components of the economy, causes and environmental impact of economic growth. This article reviews the relationship patterns between economy and ecology considering the abovementioned. This approach to the analysis implies semantic interpretation of the economic factors, mechanisms, and structures as part of the environmental issues. To formalize the said processes, we use the cognitive model defined in the graph theory as a signed digraph [9]. Such cognitive model allows to obtain a holistic view of the existing eco-economic process through its graphic representation reflecting nature and dynamics of causal relationships.

\section{Results}

The primary focus of traditional models describing manufacturing processes is on economic procedures while environmental issues being shifted towards the periphery $[10,11]$. The cognitive model of the eco-economic process shown in Figure 1 represents particularly this kind of correlation in the economy-ecology system. A primary cycle, namely the production circuit, lies at the core of the model and includes, in a more general case, such variables as Purchases, Production, Sales and Revenue consecutively linked with one another. Besides, this circuit also makes up a microcircuit with the variable Investments. All circuit gains between the variables are positive and hence allow to generate the positive feedback cycles (marked with the "+" symbol inside the circular arrow). 


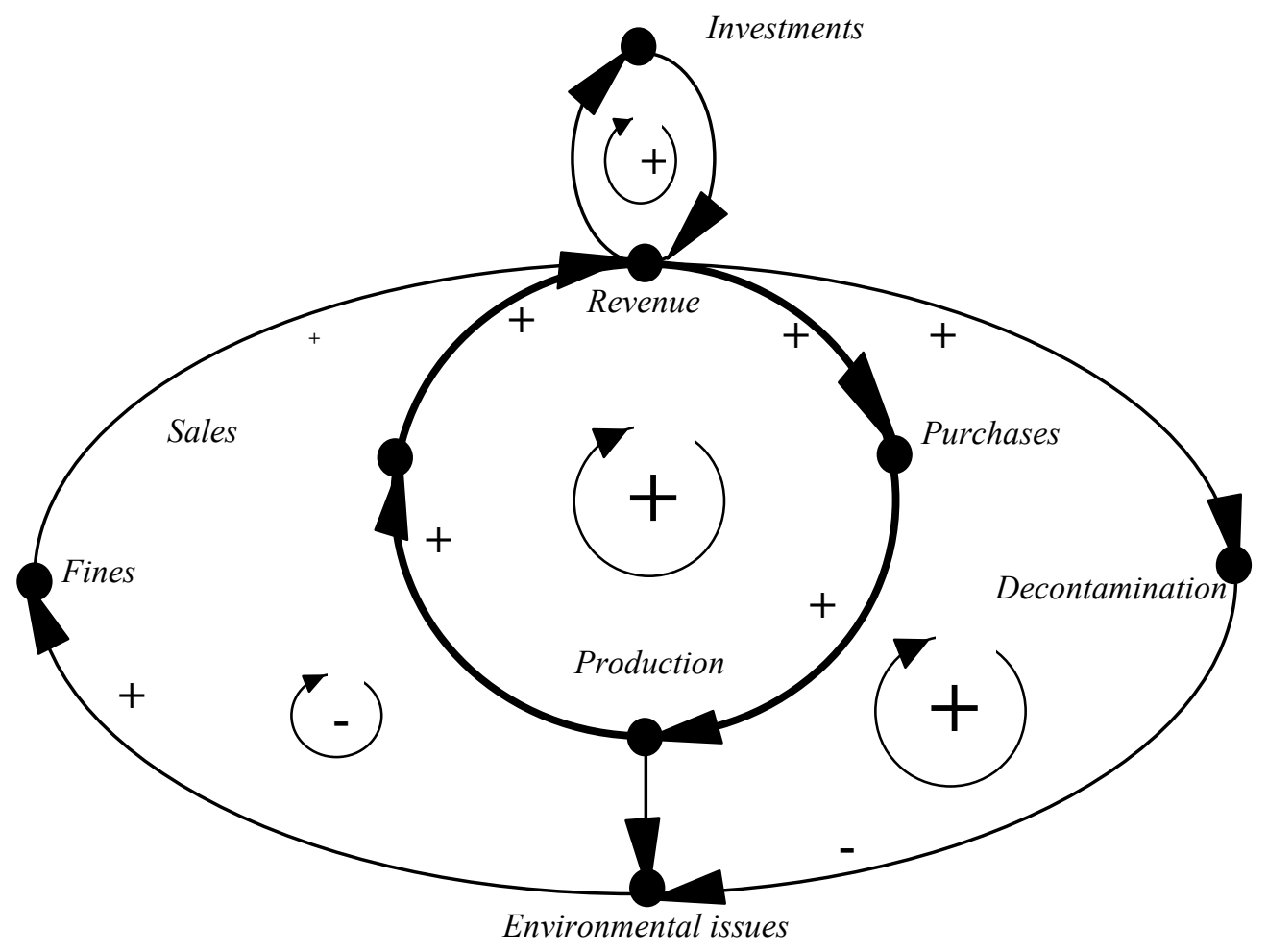

Fig. 1. Cognitive model of the traditional eco-economic process.

These cycles are defined as growth cycles and aimed at generating revenue as a result of manufacturing. Hence, the natural desire of enterprise owners and management is to increase production efficiency, sales, investments and, eventually, to enhance rationality and adequacy of purchases. Therefore, violations of the environmental regulations (the variable Environmental issues) occurring in the process of production are dealt with outside the primary circuit.

In fact, the variable Environmental issues are introduced into the model due to the variable Production (the former is related to the latter) but semantically forms a separate circuit together with the variable Fines. The amount of fine is determined in accordance with the severity of the violence (the arc with the "+" symbol) that results in decline in revenue (the arc with the "-" symbol). Consequently, a newly shaped circuit with the variable Environmental issues now employs negative feedback (marked with the "-" symbol inside the circular arrow). Mitigation of ecological footprint in this circuit is achieved merely by the production cutback (reduction of revenue will be followed by purchase cutback and reduced level of production).

However, fines are not the only trouble an enterprise faces with relation to the environmental impacts from production. It is also forced to allocate a part of its financial means for ecological restoration (the variable Decontamination). In essence, it is the variable Decontamination that shapes the outer circuit as against the primary production circuit. This circuit is comprised of such variables as Decontamination, Environmental Issues, Fines and Revenue. This is kind of a coercive measure that impels enterprises to mitigate their environmental damage. Unfortunately, production development in the specified model is essentially confined by the environmental requirements while 
environmental condition is inevitably impacted and demands further restoration or, at the very least, decontamination. It is obvious that imminent strengthening of the ecologic requirements compels enterprises to switch over their corporate development plans to innovative models of production with different insights into the eco-economic relations.

\section{Discussion}

Therefore, at the present stage the traditional approach to the production development may no longer be considered as appropriate. The new approach is required that will be premised on the principle of production excluding generation of waste in general and environmentally hazardous waste in particular. Those enterprises that implement such principle are named zero-waste enterprises (ZWE) while the technologies used by them are named zero-waste or sustainable technologies. As noted in [12], "such approach draws from nature itself. In natural ecosystems the processes of production and degradation of the living substance are balanced, biowaste of some organisms serves as a habitat for the others that results in a virtually permanent circulation of substances." This idea was engendered in the middle of the $20^{\text {th }}$ century but only recently the zero-waste technological processes turned into an emerging trend at the production enterprises. New manufacturing organization models must aim to improve human environment as a whole and base on the zero-waste production principle where underused resources and raw materials are considered as waste.

The above-described idea is represented in Figure 2 in the shape of a cognitive model of sustainable production. In this model the environmentally unfriendly production (refer to the variable Production in Fig. 1) is substituted with the sustainable zero-waste production (the variable ZWP).

However, such simple substitution allows to essentially change both the structure and the operation of the enterprise. Similar to the previously reviewed traditional model, the variables Purchases, ZWP, Sales and Revenue constitute a positive feedback circuit that manifests the cycle of enterprise growth. At that each variable of the primary circuit is also a core variable that is integrated into the auxiliary circuits together with their features [9] in order to support and develop the main circuit with $Z W P$. Multiple circuits of this model represent the propensity of the auxiliary circuits for integration into the zero-waste production cycle. Each of the four auxiliary circuits incorporates two variables of the primary circuit. Considering that all circuits employ positive feedback (marked with the "+" symbol inside the circular arrow), they initiate growth and mutually support consistent operation of an enterprise. 


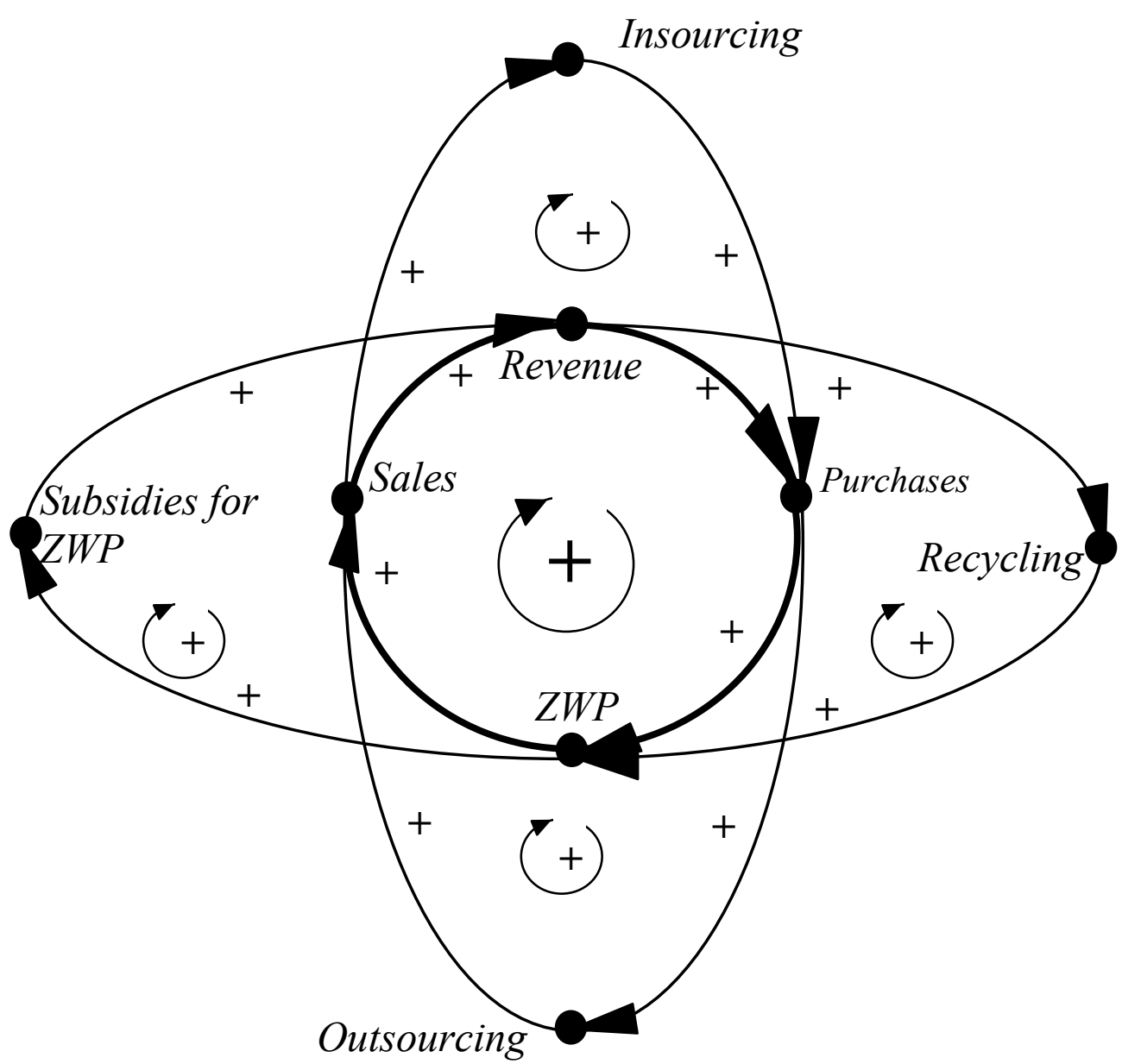

Fig. 2. Cognitive model of sustainable production.

For example, in this model $Z W P$ operation is ensured by the intended purchases of raw materials (the variable Purchases in the primary circuit), however, its development is further propelled by the variable Recycling inbuilt into an auxiliary circuit. In this case the variable Recycling provides an opportunity to employ waste recycling technologies in the production cycle [13] and simultaneously lifts off the burden on the variable Revenue when purchasing raw materials. Here the variable $Z W P$ integrates features of the variable Purchases in the primary circuit together with those of the variable Recycling in an auxiliary circuit. As a result, an enterprise saves on raw materials, reduces the volume of waste, and eliminates negative impact on the environment.

The variables Insourcing and Outsourcing are built into the model for the same reason. In this model employment of the outsourcing and insourcing technologies is intended to outline the complimentary circuits in order to support sales (if the burden is lifted off the main production unit) and utilize resources developed within the organization when planning purchases $[14,15]$. In each case an enterprise achieves lower excess capacity cost when the method of insourcing allows to trade the excess capacity and the method of outsourcing, on the contrary, involves outsourcers into the zero-waste production circuit. The above described auxiliary circuits surround the primary circuit tangentially (at two core points marked by the variables Sales and Purchases). In a newly shaped circuit Sales $\rightarrow$ 
Insourcing $\rightarrow$ Purchases $\rightarrow$ Outsourcing the availability of the insourcing opportunities determines demand of the enterprise for outsourcing. Hence, a zero-waste enterprise can and should develop in cooperation with other enterprises that consciously or implicitly (formally) implement sustainable manufacturing plans.

Since building alliances between sustainable enterprises is a natural process, receiving financial support is just as natural. Society interested in the green manufacturing is not going to give a complete control over zero-waste production to commercial and investment ventures. The present model suggests using one of the available financial aids, namely, subsidies. Much attention is deservingly paid to this issue in academic literature (refer, for example, to [16]). Here, we propose to use the most suitable in this circumstance financial instrument that is a subsidy for zero-waste production (the variable Subsidy for ZWP). This financial aid is granted in a form of gratuitous and irrevocable inter-budgetary transfers to companies, individual entrepreneurs, and individuals as a contribution for lost income and (or) financial provision. This definition places the variable Subsidy for ZWP directly into the circuit with the variable Revenue. In executing social instructions for environmental protection, the Government should not only compensate for lost income. The granted subsidy should potentially provoke ZWP to join sustainable enterprise alliances (an alluring possibility of establishing tight control of the appropriate use of the granted funds is also worth noting).

\section{Conclusions}

1. Cognitive analysis revealed that production development following the traditional model is essentially limited by the ecological requirements while environmental condition is inherently impaired and requires further restoration or, at the very least, decontamination.

2. New models of manufacturing organization must aim to improve human environment as a whole and base on the zero-waste production principle where underused resources and raw materials are considered as waste.

3. A cognitive model of green manufacturing features a multi-circuit system with all the circuits included in the zero-waste production cycle. Considering that all circuits employ positive feedback, they initiate growth and mutually support consistent operation of an enterprise.

4. A zero-waste enterprise can and should develop in cooperation with other enterprises that consciously or implicitly (formally) implement sustainable manufacturing plans.

\section{Acknowledgements}

The current research was carried out as a part of the scientific project No. ВНГр-07/202005-ФП and funded from the budget of the Southern Federal University.

\section{References}

1. P.V. Druzhinin, G.T. Shkiperova, Problemy prognozirovaniya 1, 88-97 (2012)

2. P.V. Druzhinin, M.V. Moroshkina, G.T. Shkiperova, Vestnik Permskogo universiteta, seriya Ekonomika 2(21), 15 - 23 (2014)

3. N.N. Yashalova, Nacional'nye interesy: prioritety i bezopasnost' 11, 33-40 (2013)

4. T.A. Bojchenko, Nauka. Innovacii. Obrazovanie 1(27), 26-46 (2018)

5. R. York, E.A. Rosa, T. Dietz, Ecological Economics 46(3), 351-365 (2003)

6. B. Warr, R. Ayres, Ecological Economics 73, 93-102 (2012) 
7. A.M. Starostin, Gosudarstvennoe i municipal'noe upravlenie. Uchenye zapiski 2, 9-20 (2014)

8. A.G. Kobilev, M.D. Rozin, A.L. Malyuga, V.P. Svechkarev, Vestnik Rostovskogo gosudarstvennogo ekonomicheskogo universiteta (RINH) 2(66), 36-42 (2019)

9. V.P. Svechkarev, Cognitive analysis of social problems: a textbook (Izd-vo RO RIA, Rostov-na-Donu, 2019)

10. K.V. Nikolaeva, A.A. Sagdeeva, O.N. Grigor'eva, Vestnik Kazanskogo tekhnologicheskogo universiteta 16(20), 335 - 339 (2013)

11. M.D. Rozin, V.P. Svechkarev, A.L. Malyuga, Inzhenernyj vestnik Dona 4 (2018) ivdon.ru/ru/magazine/archive/n4y2018/5225

12. N.P. Tarasova, V.A. Zajcev, V.A. Kuznecov, Uspekhi v himii i himicheskoj tekhnologii 28(4), 19-22 (2014)

13. A.V. Rassoha, Universum: Ekonomika i yurisprudenciya 6(39), 60-65 (2017) http://7universum.com/ru/economy/ archive/item/4873

14. C.W. Jong, University of Missouri Academy of Entrepreneurship Journal 1, 13-32 (2015)

15. N. Tulebayeva, D. Yergobek, G. Pestunova, A. Mottaeva, Z. Sapakova, E3S Web of Conferences 159, 01012 (2020) https://doi.org/10.1051/e3sconf/202015901012

16. T.N. Sedash, Finansy i kredit 7(631), 54-62 (2015) 